\title{
LIMITES DO ROMANCE: INOVAÇÃO E EXPERIMENTAÇÃO EM JACQUES LE FATALISTE ET SON MAÎTRE
}

\author{
LIMITS OF THE NOVEL: INNOVATION AND EXPERIMENTATION IN JACQUES LE \\ FATALISTE ET SON MAÎTRE
}

\author{
Evaneide Araújo Silva \\ UNESP - Araraquara
}

\begin{abstract}
RESUMO: este trabalho concentra-se em fazer uma análise do romance Jacques le fataliste et son maître (1778), do escritor e filósofo francês Denis Diderot (1713-1784), no sentido de demonstrar como essa obra dá, na própria estrutura da narrativa, uma resposta muito original e legítima às questões que se colocava ao gênero no século XVIII: afinal, o que é o romance? Como fazer para buscar a verossimilhança dentro da narrativa? A que se presta um romance? Qual a sua finalidade e quais devem ser as características principais que o distinguem da poesia, do drama e da História? Trata-se, portanto, de demonstrar a importância de Jacques le fataliste para a evolução do próprio gênero ao colocar em evidência procedimentos e temas literários inovadores, transformando o falso - a ficção - em uma forma de declarar a verdade e de discutir os problemas históricos de seu tempo.
\end{abstract}

PALAVRAS-CHAVE: História do romance; Jacques le fataliste et son maître; Forma romanesca.

ABSTRACT: this work focuses on making an analysis of the novel Jacques le Fataliste et son maître (1778), the French writer and philosopher Denis Diderot (1713-1784), to demonstrate how this work gives, in the very structure of the narrative a very unique and legitimate response to questions that put the genre in the eighteenth century: after all, what is romance? How do it get the verisimilitude within the narrative? What "lends" a novel? What is your purpose and what should be the main features that distinguish poetry, drama, and history? It is, therefore, to demonstrate the importance of Jacques le Fataliste for the evolution of the genre itself to highlight innovative procedures and literary themes, making the false - fiction - in a way to declare the truth and discuss the historical problems of his time.

KEYWORDS: History of the novel; Jacques le Fataliste et son maître; Novelistic form.

\section{Diderot e o contexto do romance no século XVIII}

Denis Diderot (1713- 1784) sempre foi conhecido como um dos filósofos da Encyclopédie. No entanto, o que o grande público ignora é que ele não exerceu apenas atividades intelectuais ligadas à filosofia: Diderot possui uma extensa produção ligada às artes: música, teatro, literatura, artes plásticas. No campo literário, conta-se uma vasta produção que inclui contos, ensaios, peças de teatro e romances. Como autor literário, 


\section{Revista do SELL \\ v. $4, n^{\circ} .2$ \\ ISSN: $1983-3873$}

Diderot sempre foi uma figura no mínimo estranha para o seu tempo: seus textos eram comumente vistos como confusos e fora dos padrões literários do século XVIII. Dentre as narrativas mais conhecidas estão $O$ sobrinho de Romeu e Jacques o fatalista e seu amo.

Jacques o fatalista o fatalista e seu amo, obra publicada pela primeira vez no ano de 1778, é talvez a mais conhecida de Denis Diderot. Escrita no século capital para o romance enquanto gênero, essa obra reflete em sua estrutura muitos dos questionamentos que se colocava ao romance no século das luzes. O século XVIII foi, por assim dizer, "a hora e a vez do romance", no sentido de que esse grande gênero, que de fato já era amplamente apreciado pelo público leitor, começa a se definir e a ganhar espaço entre os gêneros literários de prestígio. Do ponto de vista prático, o romance sempre existiu; não é uma invenção do século XVIII. De acordo com Bakhtin (1988), as narrativas, desde a Antiguidade clássica, se estruturavam segundo duas premissas básicas: narrativas "elevadas" e narrativas "baixas". Essas duas classificações propostas por Bakhtin levam em conta o tema, os personagens e a própria estrutura dos textos. $\mathrm{Na}$ categoria de narrativas elevadas estariam os romances de cavalaria, por exemplo, que tratavam de temas clássicos, ligados à cultura greco-latina. Já na linha dita "baixa" incluíam-se as paródias, as comédias, os textos que de alguma forma deixavam de lado o gosto pela cultura clássica. Essa perspectiva adotada por Bakhtin representa uma dualidade importante na história da evolução do gênero romanesco: a oposição entre romance "romântico" e romance "realista", sendo que Dom Quixote foi o grande marco dessa dualidade, e a forma realista começa a figurar cada vez com mais importância na formação desse gênero plural que é o romance. Já no século XVI essa dualidade começa a revelar a força do realismo. Enquanto a elite cortês reclama para si toda a cultura e refinamento através dos romances de cavalarias e das narrativas sentimentais, o romance picaresco surge (Lazarillo de Tormes é publicado em 1554), com seu herói vindo das classes baixas, despido de todo ideal cavaleiresco, com posturas indignas e ações nada louváveis. Depois veio o protagonista do principal romance de Cervantes, parodiando magistralmente o herói cavaleiro da narrativa cortês. Nessa esteira, depois da picaresca e de Dom Quixote, a tendência realista invadiu cada vez mais o mundo romanesco, e as narrativas heroicas perdiam aos poucos o seu sentido. O bom senso de uma burguesia que começava a se formar colocava-se contra as inverossimilhanças e a ênfase nos caracteres nobres, através da sátira e da paródia. Essas duas estratégias literárias serão, aliás, até o final do século XVIII, a arma preferida do romance de tipo realista para 


\section{Revista do SELL}

v. $4, n^{\circ} .2$

ISSN: $1983-3873$

desmistificar os ideais do romance cortês.

Nesse sentido, esse romance realista será durante todo o século XVIII uma literatura de oposição aos modelos clássicos, e seu tom será essencialmente de crítica social; as técnicas adotadas por seus autores revelavam sua oposição em relação a esses modelos. Os romances de linha realista, ao subverterem os moldes tradicionais das narrativas, propunham uma renovação radical na estrutura, nos temas, no modelo enfim do próprio gênero, ao mesmo tempo em que procuraram defini-lo, delimitando o seu papel no meio social e na história dos gêneros literários. Dessa forma, o herói comum, vindo "de baixo" como é o Jacques na obra de Diderot, entrou definitivamente no universo romanesco, forçando o gênero a retratar outros temas e a reinventar suas técnicas narrativas.

De fato, a ficção de linha realista tinha por característica o questionamento da forma através da experimentação de novas maneiras de narrar, da inserção de temas ligados ao cotidiano, do retrato da vida de personagens comuns, vindos das classes menos favorecidas. A proposta do romance realista, em particular no século XVIII, sempre foi questionar a forma tradicional de escrever romance e fazer com que esse gênero literário assumisse uma nova forma de se relacionar com o real. A importância desse tipo de ficção para a reinvenção do gênero se confirma no modo como os historiadores literários enxergavam esse romance. Segundo Watt (1990, p. 12), eles "consideravam o 'realismo' a diferença essencial entre as obras dos romancistas do início do século XVIII e a fiç̧ão posterior". Por realismo, Watt entende a maneira como o romance apresenta a vida humana, e não necessariamente na espécie de vida apresentada. Assim, segundo o autor, "o romance, mais que qualquer outra forma literária, atentou para a correspondência entre a obra literária e a realidade que ela imita" (p.13). Essa tendência demostra a capacidade que o romance de linha realista teve de questionar as formas literárias anteriores, sempre preocupadas em refletir sobre o que é humanamente universal, deixando de lado o particular e a experiência individual. Ainda de acordo com Watt (1990, p. 19), "certamente o romance se diferencia dos outros gêneros e de formas anteriores de ficção pelo grau de atenção que dispensa à individualização dos personagens e à detalhada apresentação de seu ambiente". Nesse sentido, o tempo é algo importante para o romance a partir do século XVIII: os autores começam a se interessar pelo desenvolvimento de seus personagens através do tempo, enfatizando as 


\section{Revista do SELL \\ v. $4, n^{\circ} .2$ \\ ISSN: $1983-3873$}

transformações individuais e o aprendizado trazido pela vivência. Gallagher (2009, p. 639) afirma que o desenvolvimento do gênero romance está ligado ao desenvolvimento do conceito de verossimilhança e de simulação mimética, e tais termos estão ligados ao conceito de "verdade", de "exatidão histórica". Assim, até o século XVIII, a referencialidade era vista com maus olhos pela tradição: toda narrativa que se pretendia prestigiosa deveria atentar, nos termos de Gallagher, para a "não referencialidade" ou para uma "referencialidade mais ampla", que deixava de fora o retrato das experiências individuais e, portanto, o tratamento mais realista da vida humana.

As questões como referencialidade, retrato das experiências individuais, representação do que era essencialmente humano, independente de ser ou não belo, inserção de personagens identificadas com as pessoas comuns, todas elas foram postas em primeiro plano pelos romances de linha realista. Na Inglaterra do século XVIII, os pioneiros Defoe, Richardson e Fielding deram os primeiros e mais importantes passos em direção à conceituação do gênero através de seus romances com enredos poucos tradicionais. Na França, apesar da resistência imposta pela tradição, houve escritores que, no século XVIII, deram os primeiros passos em direção à reformulação e consolidação do gênero. Diderot foi um desses escritores.

lan Watt confere à narrativa inglesa do século XVIII o título de precursora da forma romanesca moderna, caracterizada, como dissemos, pela ênfase no particular, pela individualização dos personagens, pela coesão e unidade que individualizam o romance. Já na ficção francesa do mesmo século, as novidades, segundo Watt, não eram tantas: o gosto clássico, profundamente enraizado na cultura da intelectualidade francesa, não teria permitido um desenvolvimento mais profundo da forma: o romance francês do século XVIII ainda prezava pela elegância e pelo bom gosto.

Catherine Gallagher (2009) diz que na Inglaterra o público-leitor aprendeu mais rapidamente a ler os romances como histórias fictícias. É por isso que o realismo como procedimento literário tornou-se mais maduro no século XVIII inglês se comparado à França. Segundo Gallagher (2009, p. 639), " ao que parece, essa transformação teve uma história mais complexa na França, onde a discussão sobre vraisemblance nos romance de corte foi longa e bastante sofisticada, enquanto o ato de conceituar a ficção foi mais lento". Gallagher afirma que o marquês de Croismare, amigo de Diderot, teve dificuldades em entender A Religiosa, "não apenas porque caíra no ardil preparado pelo autor, mas 


\section{Revista do SELL \\ v. $4, n^{\circ} .2$ \\ ISSN: $1983-3873$}

também porque a história parecia muito plausível e realista para ter sido inventada" (p.639).

De fato, as observações de Watt e Gallagher são justas, na medida em que na França dos séculos XVII e XVIII era demasiado difícil para os escritores, todos eles de formação clássica, introduzir elementos inovadores em suas obras, uma vez que o gosto do público, assim como a atividade crítica, não aceitavam com facilidade as inovações trazidas pela eminente Revolução Francesa. No entanto, apesar de ser possível reconhecer no romance inglês do século XVIII o precursor mais completo da modernidade literária na narrativa, não podemos deixar de destacar a importância de alguns autores franceses daquele período para a ascensão do romance enquanto gênero.

É o caso, por exemplo, de Alain René-Lesage, com o seu Gil Blas, (1715-1735) que, de acordo com Raquel de Almeida Prado (2003), apesar de conservar o preciosismo da linguagem, introduz inúmeros procedimentos inovadores em seu romance, muitos deles aproveitados da tradição picaresca: personagens mais populares, histórias que tomam por referência dados da realidade - como, por exemplo, personagens construídos a partir de figuras históricas, - espaços mais bem definidos (a Espanha - ou França - no século XVIII), a representação dos costumes, o largo uso da ironia, entre outros.

Diderot, como autor de romances, também participa dessa "revolução realista" iniciada pelos ingleses e trazida à França por autores de obra cômicas e satíricas. A fama do autor de Jacques, como dissemos, veio mais da atuação como filósofo e também crítico de arte do que de sua atividade como autor de romances. No entanto, constam de sua produção como escritor algumas obras hoje reconhecidas pela crítica como de boa qualidade estética. É o caso, por exemplo, das já citadas Les bijoux indiscrets (1748), La religieuse (1749), Le neveu de Rameau (1762), e finalmente seu romance mais conhecido, Jacques le fataliste et son maître (1778).

Nossa análise centra-se, neste momento, no caráter inovador e experimental do principal romance de Diderot, especialmente em relação ao papel do narrador e na caracterização dos protagonistas. Partimos da hipótese de que, nessa obra, Diderot procura colocar em prática suas concepções a respeito do que deveria ser um romance inovador do ponto de vista da forma. Nesse sentido, o autor de Jacques le fataliste procura, através dessa obra, propor novos paradigmas para o romance enquanto gênero, 


\section{Revista do SELL \\ v. $4, n^{\circ} .2$ \\ ISSN: $1983-3873$}

colocando em prática uma série de procedimentos que intentam afirmar a forma romanesca no sentido de diferenciar o romance não apenas da ficção tradicional, mas dos demais gêneros literários, como a poesia e o teatro.

\section{Inovação e experimentação em Jacques le fataliste et son maître}

Raquel de Almeida Prado (2003), no estudo que fez sobre Jacques le fataliste et son maître, começa referindo-se ao caráter aparentemente experimentalista dessa obra de Diderot, o que, segundo a autora, teria feito do romance "um precursor muito precoce das vanguardas literárias do século $X X "$ ( $p$. 186), experimentalismo esse que teria proporcionado um "amadurecimento da narrativa realista". Para Raquel, de fato, como Goethe já havia dito um século antes, nesse romance o único padrão parece ser o da ruptura: ruptura com os manuais que, no século XVIII, prescreviam como se fazer um romance e que eram muito frequentemente seguidos com afinco pelos escritores franceses do período. Jacques le fataliste, de acordo com a autora, cuja leitura é "quase tão divertida quanto a do Shandy, causa um certo desconforto, acentuado pelas interpelações provocativas e impertinentes do narrador, por deixar a impressão de que alguma coisa se esconde por trás da sucessão de episódios" (p. 187). Temos que concordar com Raquel de Almeida Prado, uma vez que, de fato, a estrutura da obra desrespeita completamente os padrões de composição de um romance tradicional, ainda mais se pensarmos no contexto do século XVIII, quando as regras da boa escritura vigoravam com muito mais rigidez. Para nós, leitores do século XXI já habituados a encontrar todo tipo de estilo nas obras literárias, o estranhamento é de certa forma amenizado, mas ele não deixa de existir. Esse estranhamento é em grande parte causado pela característica muito singular do narrador, que dentro da obra assume muito mais que a função de contar a história. Ele é ao mesmo tempo personagem, entrando, portanto, na diegese; também se configura como narrador heterodiegético e algumas vezes como homo e autodiegético. É claro que essa grande flexibilidade de posições na narrativa tem uma função, uma especificidade que busca um objetivo dentro do texto.

Inovação e experimentação: essas são as primeiras impressões que nos ocorrem ao ler Jacques le fataliste et son maître. Inovação porque, conhecendo minimamente a narrativa de ficção francesa do século XVIII, é evidente o tom destoante do romance de Diderot em relação ela. Em primeiro plano, a caracterização de um anti-herói com traços 


\section{Revista do SELL}

v. $4, n^{\circ} .2$

ISSN: $1983-3873$

picarescos, que mantém ao longo de sua trajetória uma filosofia de vida ridícula e incoerente, herdada de um antigo capitão, baseada no fatalismo: "[...] Jacques disait que son capitaine disait que tout ce qui nous arrive de bien et de mal ici-bas était écrit là-haut." (DIDEROT, 1970, p. 25). Jacque, como herói quixotesco, é um viajante que, ao lado de seu amo, percorre um país cujo nome o narrador não faz referência. Os dois não sabem para onde estão indo e nem porque estão indo. Portanto, não há um objetivo na viagem de Jacques e seu amo; eles simplesmente andam de um lugar a outro, e dessa viagem vão surgindo histórias, experiências e personagens que participam da trama. A falta de propósito dos personagens é logo evidenciada pelo narrador, que inicia a história de maneira nada convencional, já causando um efeito de surpresa e curiosidade no leitor: "Comment s'étaient-ils rencontrés? Par hasard, comme tout le monde. Comment s'appelaient-ils? Que vous importe? D'où venaient-ils? Du lieu le plus prochain. Où allaient-ils? Est-ce que l'on sait où l'on va?" (DIDEROT, 1970, p. 25).

De fato, para o contexto do século XVIII, não é uma maneira comum de começar uma narrativa e de apresentar os objetivos dos protagonistas. Como diz Raquel de Almeida Prado, em Jacques le fataliste o padrão parece ser a ruptura: ruptura com a forma clássica de contar história através da clareza dos objetivos da narrativa; narrar, de maneira mais tradicional possível, a história de personagens que tinham objetivos e que normalmente se estruturavam no tradicional começo meio e fim. Assim, ao ler o começo do romance de Diderot, somos surpreendidos por um narrador que nos desafia e até nos afronta ao questionar sobre nossa intenção de saber qualquer coisa sobre a história. Nesse sentido, é uma maneira clara de dizer que a narrativa que leremos nada tem de tradicional: o herói não é um homem honrado, coerente e maduro; ao contrário, Jacques é ingênuo, bobo, confuso, incoerente e até desinteressante. Sua vida nada tem de espetacular: foi um jovem que, por conta de uma surra que levou do pai, foge de casa e, por raiva, alista-se em um regimento do exército. Na primeira batalha leva um tiro no joelho e fica manco. No momento em que conta a história é um homem já de idade, mas que não tem objetivos e não sabe direito por que e para que está no mundo. Seu objetivo mais claro parece ser contar ao seu amo a história de seus amores, narração que é exaustivamente retardada pelo narrador principal, que insiste em manter um curioso e instigante diálogo metanarrativo com o leitor/narratário. 


\section{Revista do SELL \\ v. $4, n^{\circ} .2$ \\ ISSN: $1983-3873$}

Diferentemente dos heróis típicos das narrativas tradicionais, Jacques nada nos ensina do ponto de vista filosofia da Corte, mas tem muito de verdade existencial, ao se identificar com homens comuns, com vidas também comuns: ele é um anti-herói cheio de defeitos, pobre, sem grandezas, como seria qualquer francês da classe baixa no século XVIII. Ao caracterizar Jacques como um herói fora dos padrões tradicionais, supomos que Diderot pretendia confirmar sua tese de que um bom romance "não se perde jamais nas regiões do feérico"; seus personagens têm toda a realidade possível; suas figuras são tomadas do âmbito da sociedade; seus incidentes estão nos costumes de todas as nações civilizadas" (apud GUINSBURG, 2000, p. 17). E Jacques, assim como o seu amo e assim como quase todos os personagens do romance, tem mesmo toda a realidade possível, pois apresenta postura e caráter humano que reconheceríamos em qualquer sociedade e em qualquer classe social.

A caracterização geral das personagens revela a concepção de Diderot sobre a composição das mesmas, conforme exposto pelo próprio autor no ensaio "Elogio a Richardson", texto que revela muito sobre as ideias de autor de Jacques le fataliste. De acordo com Diderot (apud GUINSBURG, 2000, p.23), o leitor, ao deslizar as páginas, deve ser capaz de elaborar uma imagem concreta sobre os personagens; deve reconhecê-los nas ruas e nas praças públicas, devem inspirar "pendores ou aversões". Cada um deles deve ter suas próprias ideias, tons e expressões, e "essas ideias, essas expressões, esse tom variam segundo as circunstâncias, os interesses, as paixões, como se vê num mesmo semblante as fisionomias diversas das paixões sucederem-se". E, de fato, ao ler o romance de Diderot, observamos que os personagens, tanto os principais quanto os secundários, têm mesmo toda a realidade possível. Como dissemos, em Jacques le fataliste, a idealização dos personagens está praticamente ausente.

Outro aspecto relacionado ao caráter experimental e inovador do romance é a postura e o papel que assumem o narrador (ou narradores) e o narratário dentro da narrativa. De fato, como dissemos acima, logo no início da narrativa o leitor surpreende-se com a postura do narrador e logo se dá conta de que não se trata de uma maneira tradicional de narrar. Nesse sentido, o papel do narrador principal dentro da diegese nos parece bastante ambíguo: ao mesmo tempo em que nos deixa claro que é o condutor e tecelão da história - logo, tudo sabe e tudo vê - e que tudo o que está sendo narrado é fruto de uma "ilusão referencial", em outras partes deixa dúvidas sobre a exatidão dos 


\section{Revista do SELL \\ v. $4, n^{\circ} .2$ \\ ISSN: $1983-3873$}

fatos, alegando que não sabe o que aconteceu e que o leitor (ou narratário) deve, de acordo com suas reflexões, concluir partes da história que ele estava narrando.

É assim que, logo no início da história das andanças de Jacques e seu amo, o narrador evidencia sua posição de condutor absoluto da narração e nos surpreende ao deixar claro que todos os fatos narrados fazem parte de uma grande invenção cuja responsabilidade está em suas mãos. Nesse sentido, há uma quebra constante de expectativa do leitor, que naturalmente não se pergunta se o que está sendo narrado é ou não verdadeiro. E essa quebra de expectativa está ligada ao fato de que o romance de Diderot pretende, através da própria estrutura da narrativa, subverter as regras vigentes, incomodar o leitor acostumado à ficção tradicional, na qual o papel do narrador, em grande parte dos romances, era se manter o mais imparcial possível, narrando os fatos de forma coerente e, na maioria das vezes, linear. Assim, ao longo da história, é comum o narrador principal parar a narração e fazer indagações como essa:

Vous voyez, lecteur, que je suis en beau chemin, et qu'il ne tiendrait qu'a moi de vous faire attendre un an, deux ans, trois ans, le récit des amours de Jacques, en le séparant de son maître et en leur faisant courir à chacun tous les hasards qu'il me plairait. Qu'est-ce qui m'empêcherait de marier le maître et de le faire cocu? D'embarquer Jacques pour les îles? D'y conduire son maître? De les remener tous les deux en France sur le même vaisseau? Qu'il est facile de faire des contes! (DIDEROT, 1970, p. 26-27).

Páginas depois, atribui ao leitor possível (ou narratário) a escolha de uma versão possível para um acontecimento, evidenciando o sentido ficcional e experimentalista da narrativa: Jacques embebedara numa pousada quando estava de passagem por uma pequena cidade; o narrador principal diz não saber exatamente em que lugar do quarto ele passara a noite: se numa cadeira ou se deitado no chão, e delega ao narratário, que entra como um personagem, o dever de escolher uma das versões possíveis:

II y a deux versions sur ce qui suivit après qu'il eut éteint les lumières. Les uns prétendant qu'il se mit à tâtonner le long des murs sans pouvoir retrouver son lit $[\ldots]$.

D'autres, qu'il était écrit là-haut qu'il s'embarrasserait les pieds dans les chaises, qu'il tomberait sur le carreau et qu'il y resterait. De ces deux versions, demain, après-demain, vous choisirez, à tête reposée, celle qui vous conviendra le mieux. ( DIDEROT, 1970, p. 188).

Mas essa liberdade dada ao leitor/narratário é discretamente ignorada, quando algumas linhas depois esse narrador principal decide que Jacques passou a noite em 


\section{Revista do SELL \\ v. $4, n^{\circ} .2$ \\ ISSN: $1983-3873$}

uma cama: Jacques estava calado e queixava-se de dores no corpo, "c'était la suíte de la mauvaise nuit qu'il avait passée et du mauvais lit qu'il avait eu" (p. 188).

De acordo com categorias narrativas fixadas por Genette (1960, p. 254-255), podemos atribuir ao narrador principal do romance de Diderot três funções evidentes: além de narrar a história principal, ele também exerce as funções de regência da narrativa (discurso metanarrativo)- exemplificado no trecho que citamos acima - e de comunicação, que está profundamente centrada no diálogo constante do narrador com o narratário. Dessas três funções, a que mais parece evidenciar o propósito experimental de Jacques le fataliste et son maître é a regência da narrativa, uma vez que nós, leitores, durante toda a narrativa, somos "lembrados" de que, mesmo se tratando de um romance que busca a verossimilhança e o compromisso com a verdade humana, trata-se de uma história ficcional que, além de cumprir sua função natural de envolver o leitor numa história que alimenta a fantasia, também procura questionar as técnicas tradicionais de composição, propondo assim novas maneiras de narrar.

A presença marcante do narratário é, portanto, outro procedimento que Diderot utiliza para marcar a originalidade da obra e evidenciar o caráter ficcional da mesma, além de com isso propor uma mudança radical no uso das instâncias narrativas como forma de dar uma feição própria e inovadora ao romance enquanto gênero. Genette (1960, p. 258) faz uma distinção entre o leitor implícito e o narratário: "como o narrador, o narratário é um dos elementos da situação narrativa, e coloca-se, necessariamente, no mesmo nível diegético: quer dizer que não se confunde mais, a priori, com o leitor (mesmo virtual) de que o narrador com o autor, pelo menos não necessariamente". Assim, o narratário, que em Jacques le fataliste não é apenas um leitor implícito, está em constante diálogo com o narrador principal, questionando a verdade dos fatos, propondo soluções, tentando adivinhar a sequência das histórias que são narradas. Desse modo, ele é um personagem como qualquer outro dentro da narrativa, e mais do que um personagem, sua função vai além: ele constrói, junto com o primeiro narrador, a história de Jacques e do amo. No curioso diálogo que segue entre o narrador principal e o narratário, esse fato fica demonstrado. Aqui, o primeiro narrador diz que poderia fazer o que quisesse com o destino de Jacques, mas seu apego à verdade dos fatos o impede de agir assim. Em resposta, o narratário, fazendo as vezes de crítico literário, questiona essa fidelidade que pode acabar tornando o relato sem graça: 


\title{
Revista do SELL
}

v. $4, n^{\circ} .2$

ISSN: $1983-3873$

\begin{abstract}
[...] mais quelle autre couleur n'aurais-je pas été le maître de lui donner, en introduisant un scélérat parmi ces bonnes gens? Jacques se serait vu, ou vous auriez vu Jacques au moment d'être arraché de son lit, jeté sur un grand chemin ou dans un fondrière . - Pourquoi pas tué? - Tué, non. J'aurais bien su appeler quelqu'un à son secours; ce quelqu'un là aurait été un soldat de sa compagnie: mais cela aurait pué le Cléveland à infecter. La verité, la verité! - La verité, me direz-vous, est souvent froide, commune et plate; par exemple, votre dernier récit du pansement de Jacques est vrai, mais qu'y a-t-il d'intéressant? Rien. - D'accord. (DIDEROT, 1970, p. 59).
\end{abstract}

Ao subverter totalmente o uso das instâncias narrativas em favor de uma discussão maior - a renovação dos artifícios romanescos e por consequência a renovação da forma romanesca - o romance vai assim construindo um verdadeiro debate literário dentro da própria obra. O recurso à metaficção, portanto, é mais uma técnica utilizada por Diderot para não só refletir sobre a especificidade do romance, mas uma forma de desconstrução, de crítica ao gosto contemporâneo. É nessa linha que narrador e narratário refletem sobre os processos de composição; comparam a história de Jacques e seu amo com outras obras do século XVIII - por exemplo, o Cléveland (1732-1739), de Abade Prévost - ou mesmo Molière e Richardson: "S'il faut être vrai, c'est comme Molière, Regnard, Richardson, Sedaine; la vérité a ses côtés piquants, qu'on saisit quand on a du génie [...]. (DIDEROT, 1970, p. 59)

Ao ler a obra de Diderot e refletir sobre sua forma, supõe-se, portanto, que o romance Jacques le fataliste et son maître é inovador, na França do século XVIII, em todos os sentidos. Em primeiro lugar, as categorias narrativas (narrador, personagens, narratário, tempo, espaço, história, etc.) assumem uma função totalmente nova dentro da obra; não se trata de um narrador comum, que se coloca como um simples contador de histórias, mas de um articulador irônico, um crítico de si mesmo e de seus procedimentos; assim como o narratário não tem apenas a função de mais um personagem dentro da diegese, mas, ele também, assume a função de artesão da narrativa, colocando-se como um leitor e crítico sagaz, que está de olhos e ouvidos bem abertos, espreitando cada comentário ou forma de contar do narrador principal.

$\mathrm{Na}$ obra de Diderot, essas categorias constituintes da narrativa estão desconstruídas, assumem uma função que vai além da composição da diegese, em favor da reflexão principal que a obra veicula, qual seja, pensar a constituição do romance enquanto gênero, estabelecer novos paradigmas para a prosa de ficção. Vemos, portanto, que Jacques le fataliste et son maître confere, na própria estrutura da narrativa, uma 


\section{Revista do SELL \\ v. $4, n^{\circ} .2$ \\ ISSN: $1983-3873$}

resposta muito original e legítima às questões que se colocava ao gênero no século XVIII: afinal, o que é o romance? Como fazer para buscar a verossimilhança dentro da narrativa? A que se presta um romance? Qual a sua finalidade e quais devem ser as características principais que o distinguem da poesia, do drama e da História? É nessa esteira que é possível fazer o velho e conhecido pacto de "suspensão voluntária da incredulidade", viajando na leitura de uma história divertida e surpreendente, e também refletir, como leitor maduro e estudioso, sobre uma narrativa cujo objetivo maior parece ser questionar a si mesma e por consequência o gênero ao qual pertence.

\section{Considerações finais}

Ao ler e refletir sobre o conteúdo e a forma de composição desse romance, percebemos que a obra põe em cena uma série de procedimentos e técnicas que têm como principal objetivo discutir o fazer literário (metaficção), como forma de radicalizar e combater as velhas técnicas adotas tradicionalmente nas escrituras dos romances, propondo dessa maneira uma renovação profunda na forma romanesca através do uso incomum das várias categorias da narrativa: narrador, tempo, espaço, descrições, personagens, linguagem, além da mistura propositada de gêneros - romance, conto, reflexões filosóficas. Jacques le fataliste, nesse sentido, pode ser lido como um grande tratado sobre como se fazer um romance coerente com as transformações que o gênero fatalmente exigia no século XVIII. Assim, vemos como Diderot constrói de forma muito singular esse tratado ficcional; a obra procede a um duplo movimento: ao mesmo tempo em que materializa as técnicas mais comuns utilizadas nas narrativas do século XVIII, o romance faz a negação de todas elas ao praticá-las, como que transmitindo a seguinte mensagem: um romance ruim é feito assim, com longas descrições e histórias encaixadas que não têm qualquer ligação com a principal, suspensões desnecessárias, narradores que tudo sabem, inverossimilhanças de todos os tipos, histórias de amor que não encontram qualquer correspondência com a realidade. E se um mau romance é assim construído, por outro lado, uma narrativa de qualidade deve primar pela busca da verdade, pela verossimilhança dos fatos narrados, pela construção lúcida dos personagens, dos espaços e do tempo. 


\section{Revista do SELL}

v. $4, n^{\circ} .2$

ISSN: $1983-3873$

\section{Referências bibliográficas}

BAKHTIN, M. Questões de literatura e de estética: a teoria do romance. Tradução de Aurora Fornoni Bernardini et al. São Paulo: Unesp/Hucitec, 1988.

DIDEROT, D. Éloge de Richardson. In: GUINSBURG, J. (Org.) Diderot: estética, poética e contos. São Paulo: Perspectiva, 2000. p. 15-28.

DIDEROT, D. Jacques le fataliste et son maître. Paris : Garnier-Flammarion, 1970.

GALLAGHER, C. Ficção. In : MORETTI, F. (Org.). A cultura do romance. São Paulo : Cosac Naify, 2009, p. 629-658.

GENETTE, G. Discurso da narrativa. Tradução de Fernando Cabral Martins. Lisboa: Vega, 1960.

PRADO, R. A. A jornada e a clausura. São Paulo: Ateliê, 2003.

WATT, I. O realismo e a forma romance. In: ------. A Ascensão do romance: estudos sobre Defoe, Richardson e Fielding. São Paulo: Companhia das Letras, 1990. p. 11-33. 